Textures and Microstructures, 1991, Vols 14-18, pp. 813-818 Reprints available from the publisher

Photocopying permitted by license only
(C) 1991 Gordon and Breach Science Publishers SA Printed in the United Kingdom

\title{
HOT ROLLING TEXTURES IN FERRITIC STEELS AND TEXTURE DEVELOPMENT IN THE FOLLOWING PROCESSING STAGES
}

\author{
CORNELIA DÄRMANN-NOWAK, BERNHARD ENGL \\ HOESCH STAHL AG, Dortmund, FRG
}

\section{INTRODUCTION}

The production of deep drawing sheet steel is characterized by a number of different processing steps including casting, hot rolling, cold rolling and annealing. The final material properties are related not only to the last production steps but also to the foregoing processing parameters. As the above-mentioned properties strongly depend on the materials textures it is necessary to investigate in addition to the cold rolling and annealing textures the hot rolling textures as well. It was the aim of the present investigation to have a closer look at the hot rolling textures of different deep drawing steel grades. Additionally, special interest is given to the textures of the following production steps, i. e. cold rolling and annealing.

\section{EXPERIMENTAL PROCEDURE}

Experiments have been carried out on several aluminium-killed mild steels with a carbon content of about $0,03-0,04$ weight $\%$ and on vacuum degassed titaniumalloyed $\mathrm{IF}(=$ Interstitial Free)-steels $(\mathrm{C}<0,01$ weight $\%$ ) which have commercially been hot rolled varying the finishing temperature (FT). In all cases the coiling temperature was situated between 670 and $680^{\circ} \mathrm{C}$. The cold rolling with a thickness reduction of $75 \%$ and the short-time annealing at $800{ }^{\circ} \mathrm{C}$ (soaking time about $1 \mathrm{~min}$ ) have been done in the mill as well as in the laboratory.

Because of the well-known significant hot rolling texture variation along the sheet thickness direction ${ }^{1}$ the texture measurements (Mo- $\mathrm{K}_{\alpha}$-radiation, back reflection mode) of the hot rolled specimens have been carried out at different thickness levels, i. e. near the surface, at the 
$50 \%$ layer between surface and mid-thickness, and in the middle. For the cold rolled and annealed specimens only the mid-thickness texture has been measured. The results were evaluated as (110)-pole figures and in form of ODFs.

\section{RESULTS AND DISCUSSION}

Hot rolling texture

Figure 1 shows as example some results of the Alkilled steels revealing that lowering FT causes significant texture changes. In the case of the highest FT (above $\mathrm{A}_{3}$ transformation temperature) the textures generally are rather diffuse whereas lowering FT into the two-phase region between $A_{1}$ and $A_{3}$ leads to increasingly sharper textures. Strong differences exist between the textures of the surface and those of the inner layers. The former exhibit a more or less pronounced shear type character due to shearing of the outer hot band layers relatively to the inner

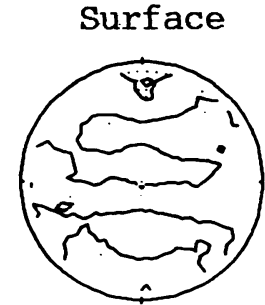

$\max .1,5$

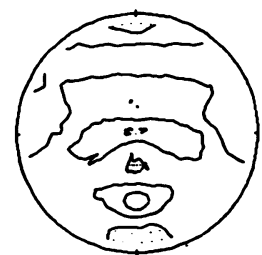

Max. 2,8

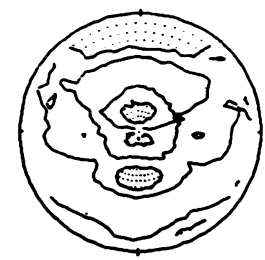

$\operatorname{mx} .2,5$

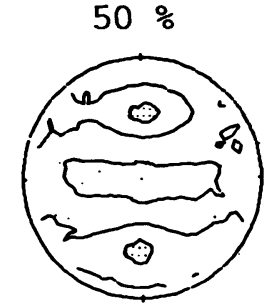

$\operatorname{Max} .1,6$

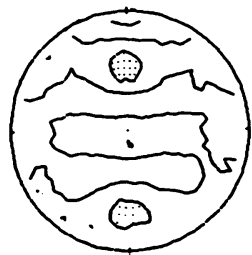

$\max .2,3$

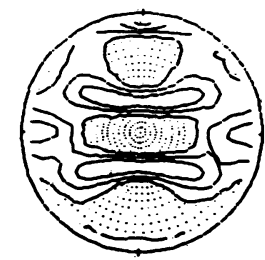

Max. 4.6

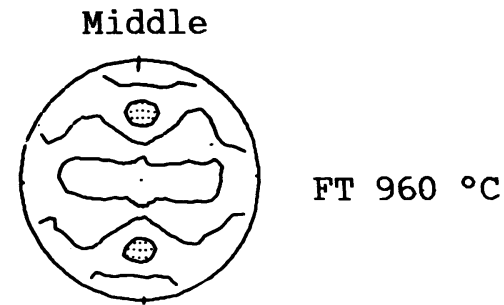

Max. 1,7

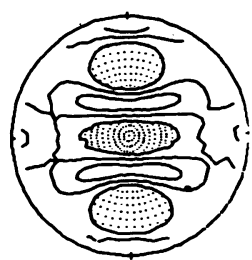

$\max .3,4$

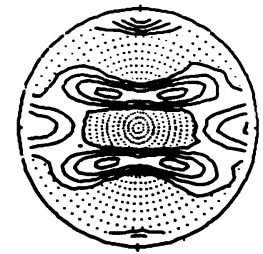

max. 5,3

FT $855^{\circ} \mathrm{C}$

Figure 1 (110)-pole figures of Al-killed steel for different FT (levels $0.5,1,2,4 \times$ random) 

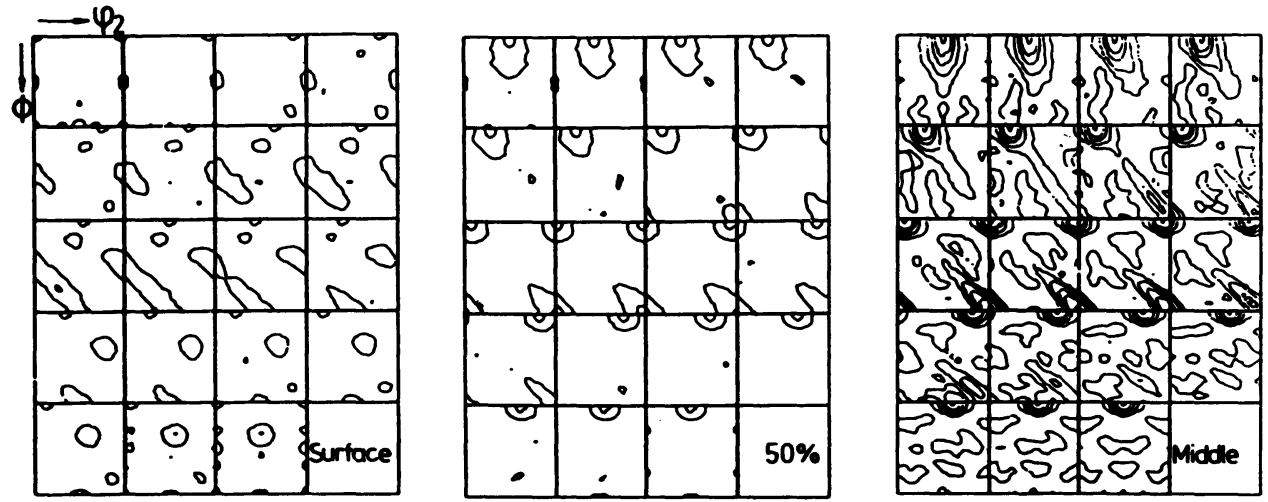

Figure 2 ODFs of Al-killed steel for FT $855^{\circ} \mathrm{C}$, $\varphi_{1}=$ const. (levels $2,4,7,10,15 \times$ random)

layer during the hot rolling process. Towards the mid-thickness level - with lower FT more clearly - typical (cold) rolling textures exist characterized especially by the increase of the $\{001\}<110\rangle$ orientation.

The ODF results of $\mathrm{FT} 855^{\circ} \mathrm{C}$ as example are given in Figure 2, the according orientation density plots along certain fibres in the Eulerian space ${ }^{2}$ in Figure 3. At the surface strong intensity on the $\rho$-fibre between (011)[100] and (011)[2 $\overline{1} 1]$ and on the $\varepsilon$-fibre between ( $\left.\begin{array}{lll}4 & 4 & 11\end{array}\right)\left[\begin{array}{lll}\overline{11} & \overline{11} & 8\end{array}\right]$ and (112)[ $\overline{1} \overline{1} 1]$ clearly indicate shear texture components. on the $\alpha$-fibre the increase of the $\{001\}\langle 110\rangle$-component can be followed from surface towards mid-thickness. The origin of the strong $\{001\}\langle 110\rangle$ could be related to the transformation of recrystallized austenite and/or strong ferrite deformation, possibly enhanced by recovering processes.
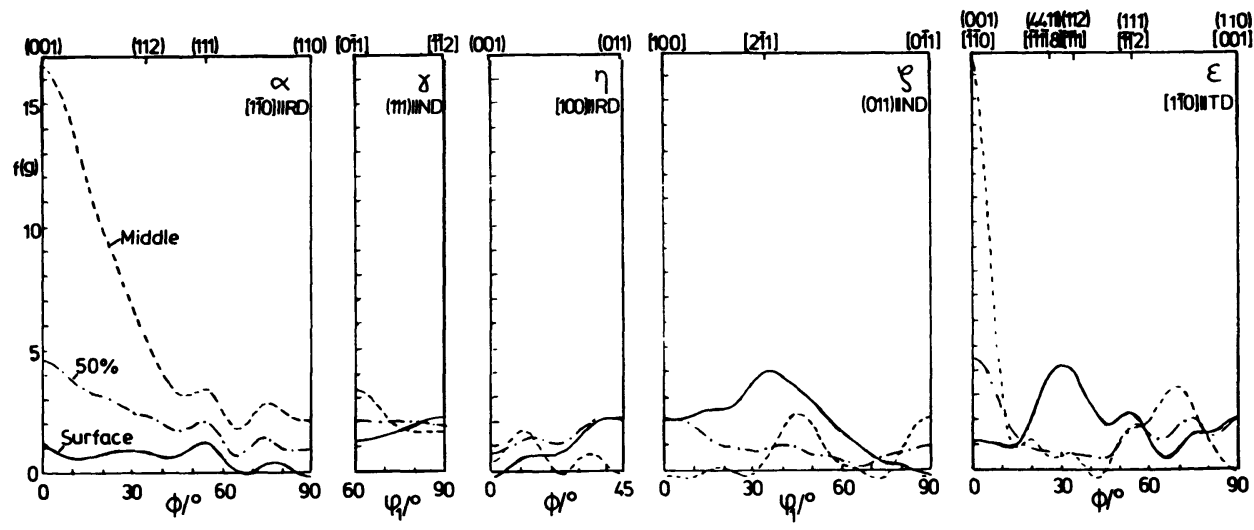

Figure 3 Orientation density along fibres $\alpha-\varepsilon$ of Alkilled steel for FT $855^{\circ} \mathrm{C}$ 


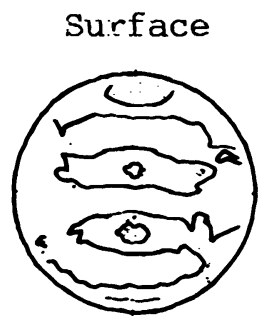

$\max .1,9$

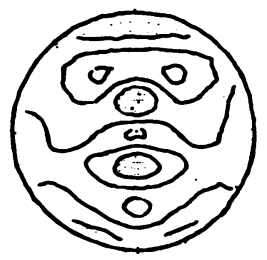

Max. 2,6

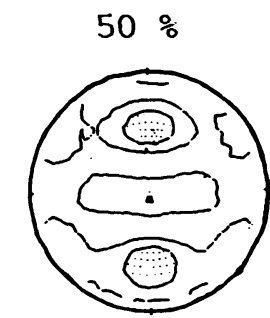

Max. 2,1

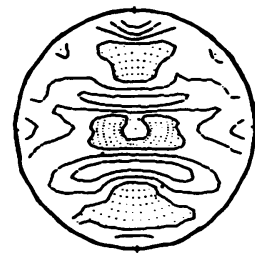

Max. 6,3
Middle

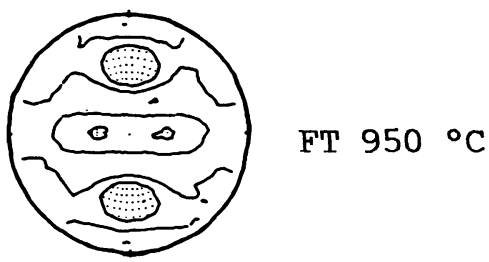

$\operatorname{Max} .2,1$

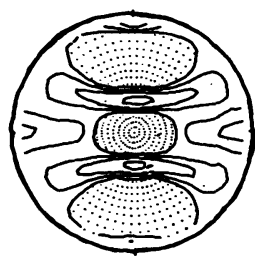

$\max .5,3$

FT $830^{\circ} \mathrm{C}$

Figure 4 (110)-pole figures of Ti-IF steel for different FT (levels $0.5,1,2,4 \times$ random)

Comparing the hot band textures of the Al-killed steels to those of the Ti-IF steels (Figure 4) both groups exhibit large qualitative similarities. A quantitative investigation based on ODF-analysis (Figure 5), however, reveals that the Ti-IF hot band textures - in addition to $\{001\}\langle 110\rangle$ - are generally characterized by significant orientation density near $\{112\}\langle 110\rangle$, possibly due to transformation of unrecrystallized austenite and/or very strong ferrite deformation (hot rolling in single phase region below $A_{1}$ in the case of low FT).
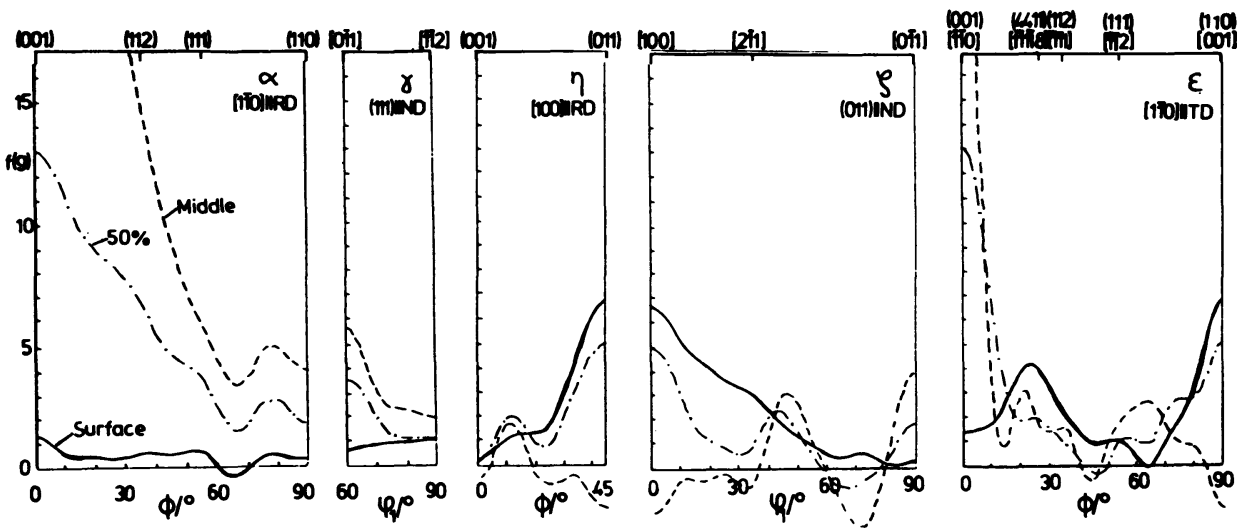

Figure 5 Orientation density along fibres $\alpha-\varepsilon$ of Ti-IF steel for FT $830^{\circ} \mathrm{C}$ 


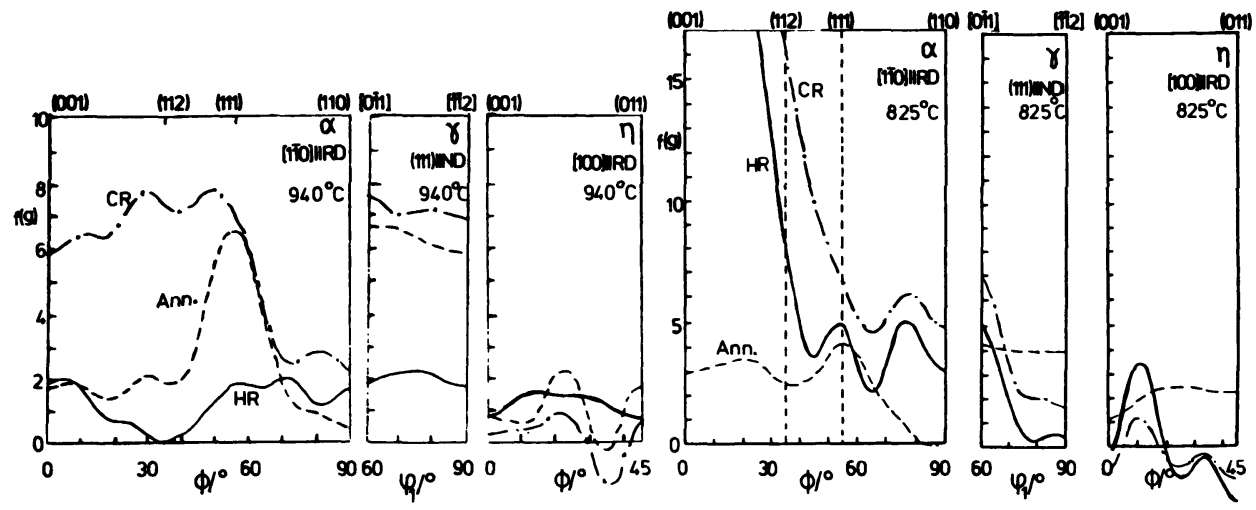

Figure 6 Orientation density along fibres $\alpha-\gamma$ of Alkilled steel for different FT

\section{Cold Rolling and Annealing Texture}

The fibre plots in Figure 6 for the Al-killed steels show that high FT exhibiting diffuse hot band textures lead to - in respect to deep drawing application - favourable $\{111\}$-textures ( $\gamma$-fibre) in the recrystallized state ${ }^{3}$. For lower FT the strong $\{001\}<110\rangle$ orientation even being enhanced during cold rolling prevents the development of the $\gamma$-fibre orientations in favour of the $\alpha$ - and $n$-fibre.

For the Ti-IF steels (Figure 7) high FT lead to - compared to the Al-killed steels - higher orientation density near $\{111\}<112\rangle$. In the case of lower FT even more significant

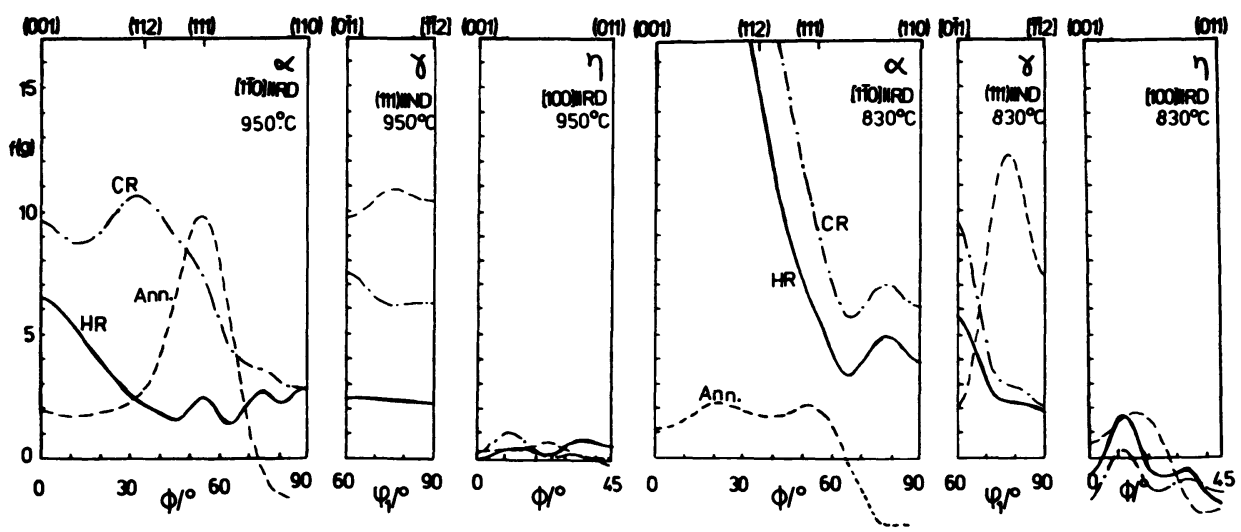

Figure 7 Orientation density along fibres $\alpha-\gamma$ of Ti-IF steel for different FT 

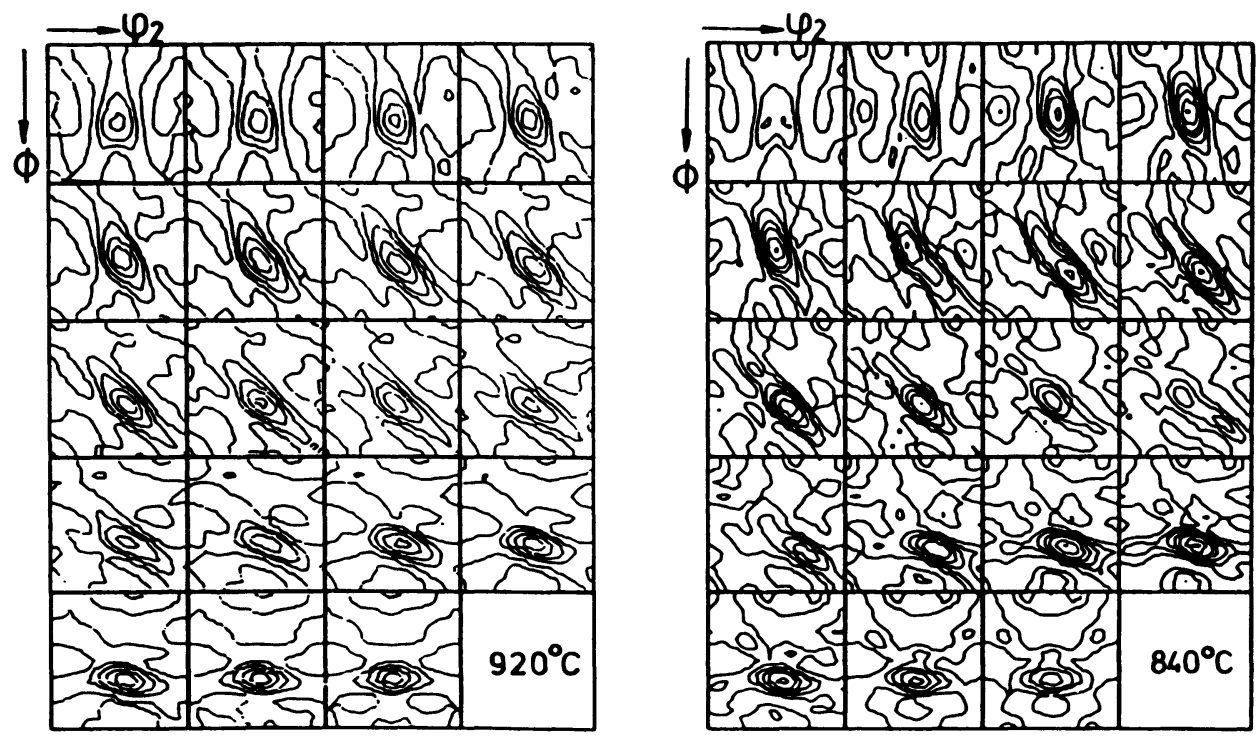

Figure 8 ODFs of Ti-IF steel for different FT, $\varphi_{1}=$ const. (levels $2,4,7,10,15 \times$ random)

differences exist (Figure 8 ) because of the development of near $\{223\}<582\rangle$ orientations after annealing which have not been known for Ti-IF steels before. They have been reported ${ }^{4.5}$ only for very high $(\geq 90 \%)$ cold rolled iron and other bcc metals with strong $\{112\}<110\rangle$ textures in the cold rolled state. Obviously due to the strong $\{001\}\langle 110\rangle-$ $\{112\}\langle 110\rangle$ hot rolling textures in the Ti-IF steels with decreased FT already lower degrees of cold rolling lead to the observed texture.

\section{REFERENCES}

1. C. Därmann, Thesis, RWTH Aachen (1983)

2. C. Därmann, M. Hölscher, S. Mishra, K. Lücke, Textures of Materials (Eds. C. M. Brakman et al.), Neth. Soc. Mat. Sci., Zwijndrecht (1984), p. 759

3. C. Därmann, B. Engl, Annealing Processes - Recovery, Recrystallization and Grain Growth (Eds. N. Hansen et al.), Riso Nat. Lab., Roskilde (1986), p. 279

4. I.L. Dillamore, Trans. Met. Soc. AIME, 233 (1965), p. 702

5. C.A. Stickels, Trans. Met. Soc. AIME, 233 (1965), p. 1550 